\title{
Press Translation in International Communication
}

\author{
Xin Xiong \\ Foreign Studies College of Hunan University of Arts \& Science, Changde City, Hunan Province, China
}

\begin{abstract}
Exchanges and cooperations between China and other countries and regions become more and more frequent in recent ten years which is impossible to be separated from translation in international communication. Nowadays, more and more people in the world are involved in the press, such as newspapers, magazines, broadcast, TV and Internet. During the course of China's going to the world stage, press translation in international communication is increasingly important. The main functions of press translation are sending messages, attracting readers and persuasion. The accurate translation of neologisms, vivid headlines and compact and brief leads can ensure the functional equivalence. In this article, I will elaborate systematically the basic features and the fundamental purposes of international communication, the basic principles and the cultural integration in press translation, and furthermore $I$ will discuss the specific solutions to the difficulties in press translation.
\end{abstract}

Index Terms - characteristics of press translation, international communication, cultural integration, equivalence translation, discourse right

\section{INTRODUCTION}

English is commonly considered to be the Lingua Franca of the world according to socio-linguistics, which means English is widely spoken in different parts of the world on different occasions, such as an international conference or a private conversation. Press English, one of the varieties of written English used, possesses its unique characteristics, which have been commonly acknowledged and studied by many people. In English, all the changes and brought by the society's advancement are best represented in mass media including newspapers, magazines, TV, radios, etc. Actually, newspapers, TV and radio have their own styles in forming part of a general journalistic pattern, which we classify them into "Press English" (Li Liangrong, 1999:101). Based on this point, this thesis is devoted to a systematic study of press translation in international communication. Previous scholars actually have made many valuable suggestions and achievements on it, and put forward some theories on some undecided issues. We are exposed to literally thousands of messages and news that inform, entertain, confuse and often irritate us. Each news item affects, in some way, the individual reading, seeing or hearing. In a word, press translation plays a vital role in international communication.

\section{INTERNATIONAL COMMUNICATION AND PRESS ENGLISH}

\section{A. Characteristics of International Communication and the Definition}

International communication is defined as a kind of one country's publicities are introduced toward the outside world, which includes publicizing a country's principles, policies, domestic situation as well as the country's stance on international issues. Communication not only performs the task of information transmission, but also plays the role of a cross-cultural messenger. Nowadays, translation is no longer merely regarded as the transmission of language symbols; meanwhile, $\mathrm{t}$ is also regarded as a mode of cultural transmission.

Translation in this article refers to several possible versions-foreign propaganda, foreign publicity, overseas information and foreign publicity. For the sake of consistency, all of them will be grouped into "international communication" from Chinese to English. Language discussed here is English; its audience refers to those whose native language or second language is English.

As a special literary form, foreign publicity, which is different from literary works, has its own characteristics that should not be ignored in translation. This requires us to do our best to make our publicity translation clear and intelligible when we introduce China to the rest of the world.

\section{B. Press English and Its Function}

With the further development in reform and opening-up, China has more and more contacts with the outside world. That is to say, there is the need for China to know about the rest of the world and for others to understand China better. For the two purposes, a large amount of information must be transmitted by news media, such as newspaper, radio, TV and Internet, among which, newspaper is the origin of press English. Press English spreading in the mass media, one of varieties of English, has its own language features and stylistic features:

a. Inform the readers or audience: the news tells what has happened locally and internationally.

b. Influence the readers: the press English sets up a different way of thinking, especially the editorials and the columns which try to express a point of view and persuade the readers or audience to "buy" an idea.

c. Entertain the readers or audience: the news English either from the foreign newspapers or the English newspapers 
in China brings various articles or programs like sports, entertainment program and so on, which add pleasure (Wang Lei, 2003:96).

Except for above three functions, press English provides a good means for college students who expect to learn English by being exposed to real English environments. Of all the media, newspaper reading seems to be the easiest and the most convenient way to get news. Reading English newspaper is one of the effective ways to gain proficiency of the English language. Many students, lacking essential knowledge of journalist English, find it difficult to understand English newspaper or the programs on VOA or BBC.

\section{Qualifications for Translators}

International communication is impossible to be away from translating press English. It is certain that the development of politics, economy and culture of a country will be included in the news. Translation is a bridge that crosses intercultural communication. During translating the news, many cultural differences existing countries will have to be translated together. What we translate is not only the names of objects and different actions, but also feelings, ways, beliefs and transfers some events relating to the world safety and human ecological environment. So, translators must have social awareness and responsibility for the national and international public, should always keep the principles of exactness, subjectivity and justice in mind.

Solid language competence is very important for a good translator who should not only be familiar with the source language, but also be a master of the target language (Bagnall Nicholas, 1993:61). Journalistic translator should love the people and language on both sides, and at the same time, he should be firmly rooted in them. Furthermore, translators must keep up with the growth and change of the language, for the development and changes of society can be reflected in the language, such as, phrase meaning may be shifted; new words and expressions may be emerging.

Culture is the soil of language. Each piece of news contains culture factors and reflects the latest development of the social culture. Language competence, in the sense of being a bilingual, is not enough, unless it is also matched by a person's being bicultural. That is to say, one must have an intimate knowledge of the culture in question. One must be able to recognize subtle ironies and literary allusions. What the translators have or haven't of the intercultural consciousness will greatly influence the translation quality. Dictionaries and encyclopedias can be very helpful in dealing with lexical problems, but they rarely go far enough in providing the kind of information which is necessary to understand the cultural differences.

\section{FEATURES OF Press ENGLISH IN INTERNATIONAL COMMUNICATION}

\section{A. Ways to Classification}

In this information era, technology makes it possible for us to carry and spread news on different mass media. So, news can be classified into many kinds.

According to different media, news is classified as newspaper coverage, magazine coverage, radio news, TV news, cable new dispatches, and the newest one-internet news. News can also be classified as world news, home news and local news according to the different locations. According to the reporting ways, news is classified as political news, technological news, cultural news, sports news, violence and crime news, weather news and disaster news, etc.

According to the qualities of the news, there are soft news and hard news. Hard news, which is also called spot news or straight news, refers to the daily news. It is a chronicle of current events or incidents and is the most common news style that is the factual account of significant news events. Soft news, a term for all the news that isn't time-sensitive, which always has more words than that of hard news, and which includes profiles of people, programs or organizations, aims at entertaining or advising the readers. You may have come across newspaper or TV stories that promise "news you can use", which might be tips on how to stretch properly before exercising, or what to look for when buying new computers.

\section{B. Structure of Press Writing}

Efficiently transmitting information requires the news must have its own style and structure leading to a quick and effective communication. News writer has different plans for different types of stories.

Pyramid structure or chronological approach: to write the news in time sequences, with the unimportant one followed by important details;

Inverted pyramid style: to organize news stories in which the essential material is placed at the beginning and subsequent paragraphs providing information in declining order of importance because the reader- especially a busy reader- always asks the most important questions first and asks unimportant questions only if he or she has time.;

A straight news story: a timely report on an event, usually written within 24 hours after the event takes place (Bruce, 2002:125). Most stories the readers read on the front page of newspapers are straight news stories. A news story is like a monologue, but this monologue is based on an imagined dialogue with the reader, and it takes shape according to what the readers want to know most. The structure of a news story is often referred to as the inverted pyramid. That is because the main and most important point is contained in the first sentence. The rest of the story contains elements of less importance as the reader nears the bottom. 


\section{C. $\quad$ Rules in Writing Press}

The headline, the lead, the body and the ending consist of the whole press news. Different rules should be followed in different parts.

In order to appeal to the readership, the translation, especially the translation of the headline, should have to meet the following rules:

a. Being specific. As with all forms of news writing, the use of specifics is better than generalities. e.g. Die as car smacks tree.

b. Being positive. Another custom most headline writers observe is phrasing headlines in a positive, rather than in a negative manner. This is based on the principle that newspaper is supposed to tell readers what did happen.

c. Expressing Opinions. Headlines on stories dealing with opinion should show the source of that opinion. If a story is attributed to a secondhand source, this should be reflected in the headline.

d. Representing the key points. One should avoid repeating words in the same headline deck. Also, watch out for similar phraseology in adjacent heads and decks. People expect newspaper stories to concern events that have occurred since the previous edition was published.

The lead as the opening sentence or paragraph must be more than just an opening to your story, which can also catch the readers' or listeners' attention and make them want to read on. Two categories are accepted as "hard" leads and "soft" leads. The choice depends on the nature of the story and determines the form of the rest of the story.

The body of the story involves combining the opinions of the people you interview, some factual data, and a narrative which helps the story flow. In a hard news story, the body supports the lead in the classic inverted pyramid style, so that the facts and quotes are written in declining importance. The body of a story can be written in other ways that depart from the inverted pyramid. One form is called the hourglass, which tries to retain the suspense of traditional, fictional storytelling. Stick to one particular theme throughout the story. You can put in different details but they all have to relate to the original idea of the piece. (e.g. If your story is about black youth and their relationship with the police you DO NOT want to go into details about the life of any particular youth). A reporter has the eyes and ears for the readers. They try to provide some visual details to bring the story to life.

The ending can be as difficult as the beginning. One way to end is with a "kicker," which is often a catchy quote. Another effective ending is to conclude with a quote or anecdote that relates the story back to the main theme and leaves the reader thinking about the essence of the story. Avoid preaching or lecturing at the end of the story. It is often hard to resist, but if the story is told well, the quotes and facts that a news writer chooses will allow the reader to come to the same conclusion on their own.

\section{The Nature, Criteria And Methods of Press Translation}

\section{A. Nature of Press Translation}

Translation is a bridge in communication on politics, economy, cultures and ideas among different nations and countries. The communication on these aspects is an activity that runs through human history, social development and cultural spread: translation of press English is the translation of a special style that has unique features, but it still agrees with the basic nature, criteria, methods and policies of translation.

Press English translation is also a science. While non-standard language usually has many kinds of proper translation methods determined by the tastes and abilities of translator himself, so translation is an art or a skill. The expressive, the informative and the vocative are the three main functions of language. The core of the expressive function is the mind of the speaker, the writer and the originator of the utterance which expresses his own feelings regardless of any response the core of the informative function of language is external situations, the facts of a topic, reality outside language, including reported ideas or theories; The core of the vocative is readership. News reporting belongs to informative text, in which statements that relate primarily to the report of the truth or the real facts of the matter has to be translated in the best style that the translator can reconcile with the style of the original.

That is to say, the translation of news reporting is the unity of science, skill and art. In fact the nature of science, skill and art should be united in the whole translation process and they are just emphasized on different degrees according to the different goals and functions.

\section{B. Criteria of Press Translation}

Since translation existed in the humans' history, the criteria of translation have always been a controversial issue. In translation there is no absolutely stale criterion. The translation should apply different criteria in terms of the text types, the feature of the times, social an cultural elements and so on.

Translation of news reporting requires agreeing with the news declarative process based on the exactness of information; the language should suit both defined and popular tastes and have the maximum readability. In the translation of news reporting, the first criterion is exactness and completeness, that is to say, the truth of the original news should be expressed accurately and it is not allowed to add or delete information freely and deliberately. The second criterion is that style of the translation should be in harmony with that of the Chinese news. After all, the readers are mostly Chinese. 


\section{Difficulties of Press Translation}

Various types of news result in the difficulties of news translation. Translators have to adapt themselves to different types of news. Most of the words, meanings, and grammatical structures used in the English news belong to everybody's English. Most of us knowing few of the "funny" expressions in the westerners' use can become fiercely significant in the translation.

How to keep concise? For translators, the first thing is to know the exact meaning of the words, then use the most appropriate words to express the meaning. But he must bear in mind that the words he uses should be concise and clear, for the space of newspaper is limited.

How to deal with the coinages and new expressions emerging continuously? With the development and globalization of economy, a large number of new words emerge to meet the needs.

How to keep faithful to the original? In translation, translators cannot distort the truth freely, he must avoid subjectivity.

The last difficulty is how the language of news reporting appeals to the reader's senses. In press English, there are some figures of speech to enrich the language, translator should say things in a way that readers find easy to relate to.

\section{Methods of Press Translation.}

In the process of translation, Peter Newmark has broken through and developed the traditional translation methods of literal and free translation, who proposed the semantic translation and communicative translation that indicate a new direction in translation studies. Communicative translation attempts to produce on its reader an effect as close as possible to that obtained on the readers of the original; semantic translation attempts to render exact contextual meaning of the original.

News reporting belongs to the informative text, and whose section containing recommendations, instructions, value judgments, etc. the following translating methods should be paid attention to:

a. Literal Translation: It is a common used and simple way of translating the news. E.g. : Helping the poor or poverty relief : in Chinese, Fuping(扶贫).

b. Free Translation. It is used when the literal translation will make misunderstand for the target readers because of the lack of related knowledge about the countries or the background of the news. E.g. to engage in speculation and profiteering: Touji Daoba(投机倒把) in China.

c. literal-free translation. When either of them cannot reach the effect of correct translation, translators will have to put the two methods together. E.g. Official document in Chinese culture, "Hongse(红色)" has been considered as authority, but for the foreign readers, "Red" may lack the imagery about Hongtou Wenjian(红头文件) in Chinese. Thus if the translators interpret at the surface as the "red document", the readers will feel puzzled. The translation combined the two methods can make them understand and to reach the purpose of spreading China overseas.

\section{CUltural Differences in Press Translation}

\section{A. Reasons Why Translators Should Know}

In press translation, cultural differences are the most difficult problem which we have to deal with. Many improper translations occur owing to being short of culture knowledge and to ignoring some idioms usage of source language. Due to different ecological, social and religious environments, each country or race forms its own culture, which takes on different characteristics, though they surely share some common ground with each other.

Press language is a comprehensive complex which breeds many cultural elements. Press language's translation is a process to convert one language to another in which culture is also transplanted. Taylor and Newmark (2001:99) defined culture as a complex whole which includes knowledge, belief, art, morals, law, customs and any other capabilities and habits acquired by man as a member of society. And the media from its function is to reach cultural aggression besides its general use of spreading or propaganda the domestic habitats. And press as a major part of the media, plays an important role in international communication, especially in spreading news outside or receiving news. Thus, to understand the different cultures will help translators to better spread the information, and the translation texts are expected to be accepted by the target readers, or the translation will fail to achieve the desired effect.

\section{B. Cultural Differences in Press Translation}

Each nationality has created its own culture. Though their cultures may have something in common, great differences still exist, particularly between oriental and occidental cultures. As one of the four ancient civilized countries, China's distinctive culture takes a significant position in modern society in the world civilization. Nonetheless, as far as cultural communication is concerned, Oriental cultures occupy subsidiary position while the western cultures the dominant position.

Without culture, language will lose its characteristics. Different languages reflect different approaches to life and ways of living as well as historical and cultural backgrounds (Liu Biqing, 1998:88). In intercultural communications, many cultural factors can be mirrored in the language. This point can be clearly expressed in press translation. Cultural differences fall into two major groups. 
On one hand, lacking of equivalents in different languages. Each country has something unique to itself. It is particularly the case in China. Very often we cannot find English equivalents for some peculiar Chinese words and expressions. In a superficial sense, this seems to be the clash of two languages while in a profound sense; it is caused by the great differences in cultures and ways of thinking between English-speaking countries and China, especially in Chinese food names, religious terms, names of cultural relics, new terms with Chinese characteristics, etc (Huang Qin, 2007:34). As they have no equivalents in English, we need to add some background explanation to make them comprehensible to foreigners.

On the other hand, the same word, the same thing or the natural phenomenon in two cultures with different meanings or connotations and reflects the distinctive local cultures. The word "yellow" can refer to color in English-speaking countries and China. Besides it can be used to describe someone who is in a depressing or gloomy state in English; On the contrary, in Chinese, it can be used as an adjective meaning "pornographic" to modify nouns such as "Huangse books(黄色书刊)” and “Huangse CDs(黄色碟片)”. The Chinese word “Huangse(黄色)” is somewhat equivalent to the English word "blue" in this sense".

\section{Influence of Cultural Factors in Press Translation}

Translation is the transformation of different languages as well as the transplant of cultures. The message encoded in one cultural may be decoded quite differently in another.

In historical process, there must be something gifted with special meanings resulting from the social heritage, such as languages have their own characteristics. For example, to westerners, the dragon is often a symbol of evil, a tierce monster that destroys and therefore must be destroyed. However, in the dynastic times in China, dragon is the traditional symbols of royalty. China has been deeply influenced by Confucianism and Buddhism, while the dominant religions of English-speaking countries are Christianity. In press English, a number of references to characters or events in the Bible can be found.

To some degree, translation from one culture to another exerts some influence on the development of a target language system by enriching it with the source language's culture-loaded words, expressions and rhetorical devices(Newmark, 1991:57). Undoubtedly, through several hundred years of cultural contacts and exchanges as well as the unremitting efforts by Chinese and western translators over the past centuries, the Chinese and western cultures now have more in common. Some words and expressions have already been absorbed by English like "kungfu" "win-win strategy" and some English words have also found their ways into Chinese like "GRE" and "rally", what's more, some more created words, especially, the translation of some set names like “superlean(酥不淢)”, “Long Kudo(龙虎斗)”, "Go Believe", etc. are being accepted by more and more western people(Xiong Xin, 2014:116). But this doesn't mean the great cultural differences will disappear in the predictable future. These differences have filtered into every aspect of society. They stand like mountains between two languages.

\section{CONCLUSION}

Translation of press English plays a very important role on politics and economy as well as in people's daily life. Press translation can bring us a great deal of latest information of the world as well as bring China to the world (Xiong Xin, 2010:100). Though it is very valuable, it is really a hard task to fulfill. Press English studies is quite different, whether on the structure or on the language.

Maybe some ideas put forward in this article are immature due to the author's limited knowledge about press English and the lack of the press translation experiences; however, the author arduously hope that it may draw more people's attention on the study of press translation, especially from Chinese to English.

\section{REFERENCES}

[1] Bruce D. Itule \&Douglas A. Anderson. (2002). News Writing and Reporting for Today's Media. America: McGraw-Hill Humanities/Social Sciences/Languages,

[2] Li Liangrong. (1999). Introduction to Journalism. Beijing: Higher Education Press, China.

[3] Wang Lei. (2003). Journalistic English. Hangzhou: Zhejiang University Press, China, China.

[4] Bagnall Nicholas. (1993). Newspaper Language. Oxford: Focal Press.

[5] Newmark, Peter. (1991). About Translation. Clevedon: Multilingual Matters Ltd.51-57.

[6] Newmark, Peter. (2001). Approaches to Translation. Shanghai Foreign Language Education Press, China. 96-99.

[7] Liu Biqing. (1998). Style and Translation. Beijing: China Translation \& Publishing Corporation.

[8] Huang Qin. (2007). A Survey and Prospect of China's News Translation Studies (vol.3). Shanghai Translation. China. 31-34.

[9] Xiong Xin. (2014). Several Problems During the Construction of the Theory of Translation Variation (vol.3). Journal of Wuling, China. 112-116.

[10] Xiong Xin. (2010). On the Status Quo of Translation in International Publicity (vol.5). Shandong Foreign Language Teaching Journal, China. 100-103. 
Xin Xiong was born in Changde, Hunan Province, China in 1973. PhD in English language and literature. He is currently an associate professor in Foreign Studies College, HUAS. Changde, Hunan Province, China. His research interests include linguistic philosophy, English language and literature \& translation.

$\mathrm{He}$ is a member of the China Society for Futures Studies and one of the executive director of China Language Education \& Study Association. 